\title{
Two-stage Comprehensive Evaluation of Travel Guidance to Road Network
}

\author{
Guo Ruijun \\ National ITS Center, Research Institute of Highway, Beijing 100088, China \\ School of Traffic and Transportation, Dalian Jiaotong University, Dalian 116028, China \\ Wang Xiaojing, Niu Shuyun, Zhang Jishen, Li Honghai \\ National ITS Center, Research Institute of Highway, Beijing 100088, China
}

\begin{abstract}
Based on the survey data of road network in west China, all kinds of cost and income were calculated during the evaluation period of the travel guidance system. The economic evaluation was rational by cost-benefit analysis, and the evaluation grade was first class by use of fuzzy AHP (analytic hierarchy process). The travel guidance to road network can be comprehensively evaluated from many aspects including technique, economy, environment etc. The two-stage comprehensive evaluation model including cost-benefit analysis and fuzzy AHP is effective in field application.
\end{abstract}

KEYWORD: Road network; Travel guidance system; Fuzzy analytic hierarchy process; Cost-benefit analysis

\section{INTRODUCTION}

The operation load of road network becomes more and more serious with rapid growing of traffic flow. The contradiction between supply of highway facilities and traffic demand still exist. There are a relatively large gap of operation supervision level of road network between China and some developed countries, such as USA, Japan, and UK and so on.

In order to satisfy demand of highway traffic partners, the mechanism and standard of data exchange was built for the travel guidance system of road network. The control platoon of operation supervision and service played a role by guidance and feedback to traffic partners. The travel guidance system can supply different-level road network platoons with technology support. It was applied in daily management, emergency guarantee and assistant decision support system and so on, so the supervision and service level was promoted.

There is much research about the impact evaluation of traffic guidance system. Mcdonald and Chatterjee (2004) considered four factors as evaluation targets including user acceptance, network efficiency, environmental impact and cost effectiveness. The relevant evaluation system was built to field VMS (variable message signs) in nine European cities. Green and Hoekstra (1993) evaluated four different patterns of route guidance by analyzing feedback message of 48 drivers. The impact evaluation to traffic guidance system was included in the item evaluation of intelligent transportation system in USA. Podvezko (2013) offered a logical control methodology for filling in the questionnaire based on the Analytic Hierarchy Process (AHP) and the sequence of calculations.

In summary, evaluation methods to traffic guidance system mainly included empirical method, statistical analysis, comprehensive evaluation method, systems approach based on multi-agent and so on. The relevant evaluation indexes should be extracted. The simulation software can be used to evaluate the effect of traffic guidance system, thereby improving traffic guidance system. The analytic hierarchical process and Cost-benefit analysis were applied in some transportation fields independently.

There was little research about travel guidance effect and field application in road network. It is worth studying how to improve original guidance program in connection with evaluation result.

\section{COMPREHENSIVE EVALUATION INDEXES}

By analyzing different kinds of effects of travel guidance system, the tri-level evaluation index system was built as Fig.1.

During assessment period, the evaluation of travel guidance was concentrated in the operation effect of road network. Travelers' time and distances can be saved by use of assisted route optimization, and the operation status of highway traffic can be improved. So the main evaluations are operation optimization of road network and improvement of traffic character. Based on traffic survey data, the energy 
consumption can be obtained by average operation distance. Final evaluation indexes were showed as Tab.1.

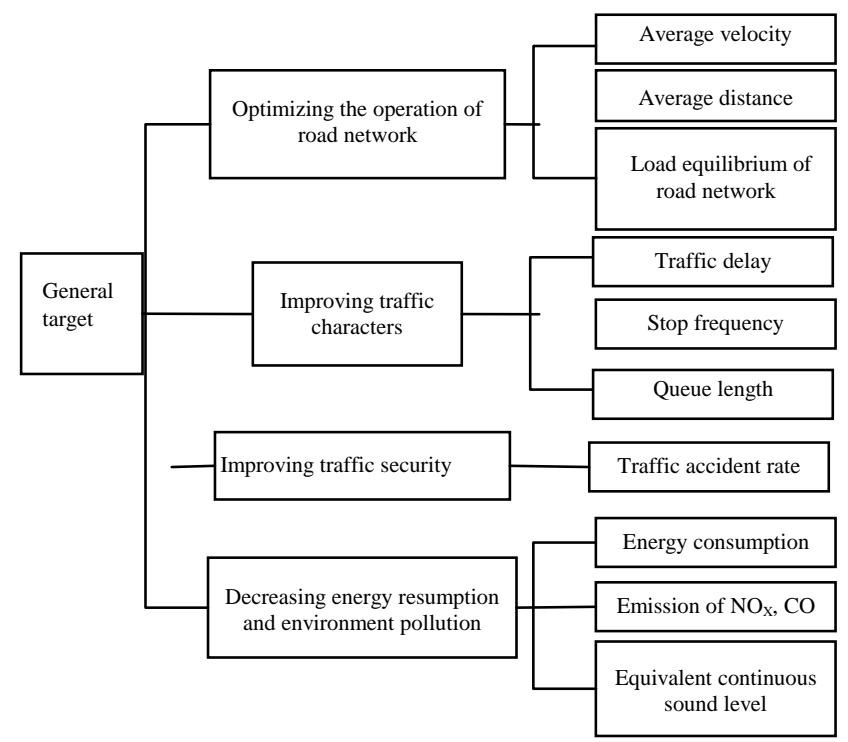

Fig.1 evaluation system of travel guidance system of road network

Tab.1 selected indexes of travel guidance system of road network

\begin{tabular}{|l|l|}
\hline \multicolumn{1}{|c|}{ Index } & \multicolumn{1}{c|}{ Meaning } \\
\hline $\begin{array}{l}\mathrm{C}_{1} \text { :Average } \\
\text { velocity }\end{array}$ & $\begin{array}{l}\text { The average running velocity involving all } \\
\text { vehicles of road network. }\end{array}$ \\
\hline $\begin{array}{l}\mathrm{C}_{2:} \text { Traffic } \\
\text { delay }\end{array}$ & $\begin{array}{l}\text { The difference between average field travel } \\
\text { time and average ideal travel time by } \\
\text { unblocked running velocity involving all } \\
\text { vehicles of road network. }\end{array}$ \\
\hline $\begin{array}{l}\mathrm{C}_{3} \text { :Average } \\
\text { distance }\end{array}$ & $\begin{array}{l}\text { The average distance from origin to } \\
\text { destination involving all vehicles of road } \\
\text { network. }\end{array}$ \\
\hline $\begin{array}{l}\mathrm{C}_{4}: \text { Queue } \\
\text { length }\end{array}$ & $\begin{array}{l}\text { The number of queuing vehicles before } \\
\text { traffic discontinuity points, such as traffic } \\
\text { congestion and traffic accident, which can be } \\
\text { estimated by the duration of traffic incidents. }\end{array}$ \\
\hline $\begin{array}{l}\mathrm{C}_{5}: \text { Energy } \\
\text { consumption }\end{array}$ & $\begin{array}{l}\text { Energy index, mean decreasing oil } \\
\text { consumption owing to optimizing route }\end{array}$ \\
\hline
\end{tabular}

In summary, five evaluation indexes were selected including four technological indexes and one energy index. These indexes' meanings were explicit and can be easily calculated. They reflected effect of travel guidance to road network in the round.

\section{THE EVALUATION METHOD}

\subsection{Two-stage evaluation model}

The usual methods of system evaluation include fuzzy comprehensive evaluation (FCE), analytic hierarchy process (AHP), data envelopment analysis (DEA) and grey comprehensive assessment (GCA) and so on. Every method had its own application scope. For GCA, the choosing resolution ratio is lack of reasonable standard, which influence the calculation of grey correlation coefficient. DEA method is an applicable to evaluate the relative effectiveness of decision making problem with multi inputs and multi outputs. It is usually applied in the evaluation of enterprise operating efficiency. But the effectiveness of decision making units can be only determined when an infinitesimal in the corresponding mathematical programming was imported.

The evaluation object was travel guidance system. Some survey data can be obtained such as building cost and traffic flow and so on, however it was difficult to obtain other data because field guidance system had not been totally finished. Because of complexity, comprehensiveness and variety of evaluation system, the single evaluation method wasn't applicative to the system.

Considering the characters of different evaluation methods and data status of travel guidance system, the two-stage comprehensive evaluation method was applied to evaluate the system. Firstly the benefitcost analysis reflected its economic effectiveness. When the economic benefit was reasonable, the FCE was used to evaluate the system with technological and social indexes, meanwhile AHP was used to determine the indexes' weight. The second step is fuzzy AHP.

\subsection{Fuzzy AHP}

Fuzzy AHP integrated FCE model and AHP model. The FCE model can be used to calculate the comprehensive evaluation vector, where the indexes' weight can be determined by AHP model. The final grade can be determined used of maximum membership principle.

The complex problem was usually divided into many elements. By analyzing relations among all elements, the multilevel hierarchical structure was built. The relative importance was determined by comparison of any two elements. Four steps were generally needed in AHP model.

(1) Building the hierarchical structure which described system's function and character.

(2) Comparing the importance of any two elements and building judgment matrixes.

(3) Single-level sequencing, that is to say obtaining eigenvalues and eigenvectors. The consistency of each judgment matrix need to be tested. If the demand of consistency wasn't satisfied, the judgment matrixc must be modified again and again till demand is satisfied.

Total sequencing. Combination weights of each level's elements need to be calculated. The consistency of total structure needs to be tested accordingly. The weight vector of indexes is as follow. 


$$
A=\left(a_{1}, a_{2}, \cdots, a_{m}\right)
$$

Based on fuzzy mathematics, FCE was a system analysis approach which can evaluate objects with fuzzy character. The calculation steps are as follows.

(1) Determining evaluation grade matrix

$$
V=\left\{v_{1}, v_{2}, \cdots, v_{n}\right\}
$$

(2) Determining the membership matrix of each object against each index. There are $m$ objects and $n$ grades.

$$
R=\left(r_{i j}\right) \quad(i=1,2, \cdots, m ; j=1,2, \cdots, n)
$$

(3) Calculating the fuzzy comprehensive evaluation vector. The weight vector $\mathrm{A}$ has been calculated by AHP model.

$$
B=A R=\left(b_{1}, b_{2}, \cdots, b_{n}\right)
$$

(4) Determining the grade by use of maximum membership principle.

\subsection{Benefit-cost analysis}

Benefit-cost analysis is a usual method in economic evaluation. According to the river and harbor act, America government regarded this method as the tool of policy evaluation since 1902. The paper used benefit-cost analysis based on total cost, which transferred both benefit and cost as present value. Calculation equations are as follows:

$$
\begin{gathered}
B / C=\frac{\sum_{t=1}^{n} B_{t}(1+i)^{-t}}{K_{0}+\sum_{t=1}^{n} C_{t}(1+i)^{-t}} \\
B-C=\sum_{t=1}^{n}\left(B_{t}-C_{t}\right)(1+i)^{-t}-K_{0}
\end{gathered}
$$

where $B_{t}$ is the net benefit, as the difference of social income and social expense of system in the No. $t$ year, $t=1,2, \cdots, n . C_{t}$ is the net operation cost, as the difference of operation spend and income of system in the No. $t$ year. $K_{0}$ is the initial investment. $i$ is the minimum required rate of return. $n$ is the operation period of system.. $B / C$ is the total benefit to total cost ratio of system, which is also the benefit per unit cost. $B-C$ is the difference between benefit and the cost, an absolute value.

For economic evaluation of the travel guidance system, it is feasible if $B / C>1$ or $B-C>0$.

Benefits of system operation included the saving travel time, decreasing travel distance, increasing travel security and saving oil consumption. Costs of system mainly referred to building cost and operation cost, in which investment subject was usually local government. Costs of travel guidance system were as follows:

(1) Investment costs, which were related to highway mileage, numbers of tunnels and bridges, the total number of vehicles through the road network, loading rate and so on.

(2) Operation costs, which were related to the total number of vehicles, the infrastructure scale and number of staff.

Benefits of travel guidance system were as follows:

(1) Save of time costs owing to increasing average travel velocity and decreasing travel time.

(2) Save of fuel consumption costs owing to decreasing travel distance, stop frequency, acceleration and deceleration frequency, and other travel costs related to fuel consumption.

(3) Save of traffic accidence cost, which can be estimated based on annual statistics of traffic accidence.

(4) The decrease of traffic pollution cost. The discharge amount of vehicles can be calculated by travel distance, velocity and stop frequency. The cost can be estimated according to historical data and empirical value in other regions.

(5) The decrease of transportation enterprises' operation cost. The additional benefit is owing to saving travel time and increasing transportation capability.

The accidence cost and traffic pollution cost were difficult to precisely quantify. The business data of transportation enterprises was difficult to collected too, so the part (1) and (2) of benefits will be analyzed and calculated. If economic demand is satisfied, it can be satisfied adding part (3), (4) and (5) too.

\section{THE TWO-STAGE COMPREHENSIVE EVALUATION METHOD}

\subsection{Benefit-cost analysis}

A travel guidance system of road network in west China involves 20 arterial highways. Total building cost of system is 34 million Yuan ( K0). The payment of first year is 800 thousand Yuan (C01). Annual maintenance cost is 2.1 million Yuan (C2). The evaluation period is 10 years (n). AADT (Annual average daily traffic) is 12000 vehicles per day (K2). The guidance system can be applied in daily operation and emergency management. Annual benefit to emergency vehicles is 1.68 million Yuan (B1) and the one for daily operation is 15.62 million Yuan (B2).

GDP (Gross Domestic Product) per capital is 6102 dollar in China, 2012. The median price of Chinese Yuan against US dollar is 6.2855 at the end of 2012. GDP per capital per hour can be calculated 
as 18.44 Yuan (a1). The fuel consumption cost per kilometer is 0.5 Yuan (a2). Steps estimating benefits are as follows about system operation.

(1) Calculation of benefits using the guidance system

The following variables are known.

Probability of emergency events (K3) is $1 \%$. The proportion of vehicles encountering emergency events (K4) is $10 \%$. Average saved travel distance (K5) is $20 \mathrm{~km}$. Average saved travel time (K6) is 0.5 hour.

The annual benefit about emergency events (B1) is as follow.

$$
\mathrm{B}_{1}=365 \mathrm{~K}_{1} \mathrm{~K}_{2} \mathrm{~K}_{3} \mathrm{~K}_{4}\left(\mathrm{~K}_{5} \mathrm{a}_{2}+\mathrm{K}_{6} \mathrm{a}_{1}\right)=1.68 * 10^{6}{ }_{\text {Yuan }}
$$

The effective proportion of vehicles daily (K7) is $2 \%$. Average saved travel distance $(\mathrm{K} 8)$ is $10 \mathrm{~km}$. Average saved travel time (K9) is 10 minutes.

The annual benefit about daily operation (B1) is as follow.

$$
\mathrm{B}_{2}=365 \mathrm{~K}_{1} \mathrm{~K}_{2} \mathrm{~K}_{7}\left(\mathrm{~K}_{8} \mathrm{a}_{2}+\mathrm{K}_{9} \mathrm{a}_{1}\right)=14.14 * 10^{6} \text { Yuan }
$$

(2) Benefit-cost analysis

The relative ratio of economic benefit is as follow by compound interest formula.

$$
B / C=\frac{\sum_{t=1}^{n}\left(B_{1}+B_{2}\right)(1+i)^{-t}}{K_{0}+C_{01}(1+i)^{-1}+\sum_{t=2}^{n} C_{2}(1+i)^{-t}}=2.45
$$

During evaluation period, the total benefit is $B=128.38$ million Yuan, and the total cost is $C=52.33$ million Yuan.

The absolute ratio of economic benefit is as follow.

$$
B-C=76.05 * 10^{6} \text { Yuan }
$$

Calculation results showed that the guidance system is beneficial.

\subsection{The comprehensive evaluation based on fuzzy AHP}

The questionnaire was designed to compare indexes' importance and evaluate the operation effectiveness of travel guidance system. The basic data is attached to the back of questionnaire.

(1) Determining indexes' weight by AHP

Meanings and notations of evaluation indexes are as Tab.1. The judge matrix of all indexes against total target is as follow.

$$
R=\left(\begin{array}{ccccc}
1 & 2 & 3 & 5 & 7 \\
1 / 2 & 1 & 2 & 2 & 3 \\
1 / 3 & 2 & 1 & 2 & 2 \\
1 / 5 & 1 / 2 & 1 / 2 & 1 & 1 \\
1 / 7 & 1 / 3 & 1 / 2 & 1 & 1
\end{array}\right)
$$

By the root-finding method of AHP, the weight vector of indexes is as follow.

$$
W=\left(\begin{array}{lllll}
0.46 & 0.23 & 0.15 & 0.09 & 0.08
\end{array}\right)
$$

(2) Fuzzy comprehensive evaluation of the system

The effectiveness was ranked into four grades including Excellent, Good, General and Bad. Questionnaires were distributed to travellers and managers. From survey result, the membership matrix is as follow.

$$
R=\left(\begin{array}{cccc}
0.67 & 0.21 & 0.12 & 0 \\
0.12 & 0.57 & 0.23 & 0.08 \\
0.33 & 0.44 & 0.21 & 0.03 \\
0.24 & 0.45 & 0.16 & 0.15 \\
0.41 & 0.32 & 0.16 & 0.11
\end{array}\right)
$$

The comprehensive evaluation vector of travel guidance system can be calculated as follow.

$$
S=W R=\left(\begin{array}{llll}
0.44 & 0.36 & 0.16 & 0.04
\end{array}\right)
$$

The evaluation grade should be Good based on maximum membership principle.

\section{CONCLUSIONS}

Usually it is difficult to obtain all operation data of many existing systems. The two-stage comprehensive model can be used to evaluate system operation effectiveness. The economic effectiveness was evaluated by the benefit-cost analysis. Comprehensive characters, which included technological indexes and social indexes, were evaluated by fuzzy AHP when the economic benefit was reasonable. Indeed the two-stage comprehensive model is fuzzy AHP based on benefit-cost analysis. The two-stage comprehensive model is effective to evaluate travel guidance system of road network.

\section{REFERENCES}

[1] Chatterjee K, Mcdonald M. Effectiveness of using variable message signs to disseminate dynamic traffic information: Evidence from field trails in European cities. Transport Reviews, 2004, 24(5): 559-585.

[2] Green P, Hoekstra E, Williams M. Further on-the-road tests of driver interfaces: examination of a route guidance system and a car phone. University of Michigan Transportation Research Institute, 1993.

[3] O. Engelhardt-Funke, M. Kolonko. Analysing stability and investments in railway networks using advanced evolutionary algorithms, International Transactions in Operational Research , 2004, 11(4), 381-394 